\title{
EFEITOS DE ACORDOS COMERCIAIS SOBRE O SETOR DE CARNE BOVINA NO MERCOSUL
}

\author{
Roberta Dalla Porta Gründling ${ }^{1}$ \\ Paulo Dabdab Waquil ${ }^{2}$
}

\begin{abstract}
Resumo: Este artigo discute as perspectivas de produção, exportações, importações, preços e níveis de bem-estar (excedente do produtor e do consumidor) para o setor de carne bovina no MERCOSUL, em face de alguns cenários de redução tarifária em nível multilateral e bilateral. Para isso, é utilizado um Modelo de Alocação Espacial formulado como um Problema de Complementaridade Mista (PCM). Obteve-se o Cenário Atual mundial de carne bovina e, a partir dele, foram simulados os cenários de redução tarifária multilateral. No Cenário Atual, MERCOSUL e Oceania são exportadores e as demais regiões produzem para consumo interno e, dentre estas, algumas são importadoras. Quando se analisa o nível de bem-estar agregado no MERCOSUL, o livre comércio multilateral é o cenário que mais traz benefícios.
\end{abstract}

Palavras-Chave: Carne bovina, Mercosul e comércio internacional.

\section{Introdução}

A Organização Mundial do Comércio (OMC) trata do comércio em termos multilaterais. Somente na oitava rodada de negociações do GATT/OMC, denominada Rodada Uruguai, foi discutido e negociado um Acordo sobre a Agricultura, que entrou em vigor a partir de $1^{\circ}$ de janeiro de 1995 e foi denominado Acordo sobre a Agricultura da Rodada Uruguai (AARU), no qual se inserem, dentre outros, o Acordo sobre a Aplicação de Medidas Sanitárias e Fitossanitárias (Acordo SPS) e o Acordo Internacional de

Economista pela Universidade Federal de Santa Maria (UFSM). Mestre e Doutoranda em Agronegócios pela Universidade Federal do Rio Grande do Sul (CEPAN/UFRGS). Email: roberta.grundling@ufrgs.br

2 Professor Associado do Departamento de Ciências Econômicas (DECON) e dos Programas de Pós-Graduação em Agronegócios (CEPAN) e em Desenvolvimento Rural (PGDR) da Universidade Federal do Rio Grande do Sul (UFRGS). Email: waquil@ufrgs.br 
Carne Bovina. Na nona rodada de negociações multilaterais e primeira no âmbito da OMC, chamada Rodada de Desenvolvimento de Doha, as discussões acerca da liberalização do comércio agrícola se aprofundaram, mas ainda não foram concluídas, em virtude de impasses, dentre eles, no setor agrícola.

Em contraponto à liberalização em nível multilateral, o processo de regionalização, caracterizado pela formação e pelo fortalecimento de blocos regionais, vem crescendo em relação aos acordos multilaterais de comércio. A proliferação de Acordos Regionais de Comércio deve-se, em parte, às dificuldades de negociações em nível multilateral. Dentre eles, podem-se citar o NAFTA, o MERCOSUL e outros acordos regionais de livre comércio entre membros da União Européia e países da Europa Central e Oriental. A formação de áreas de livre comércio, por exemplo, envolve a união de países com características distintas, diferenças que, em nível multilateral, se tornam mais acentuadas. Nos dias de hoje, os acordos vão muito além da proximidade geográfica e tornaram-se complexos e amplos (OMC, 2006).

O Brasil participa, atualmente, de diversas negociações internacionais, tanto no âmbito multilateral, visto que faz parte da $\mathrm{OMC}$, como no regional, já que integra o MERCOSUL. Nessas diversas esferas, as negociações agrícolas aparecem como ponto de crucial importância, sendo o tema da liberalização do comércio agrícola que tem ditado o ritmo das negociações. Quando se trata deste tema, são considerados aspectos econômicos, mas outras questões, como as jurídicas, políticas, sociais e sanitárias, influenciam os resultados econômicos. O estudo dos efeitos de acordos internacionais sobre o setor agrícola no MERCOSUL é importante para o auxílio nos processos de negociação, a fim de identificar quais são os possíveis ganhos e perdas para o comércio e os resultados para o bemestar dos consumidores e produtores das nações envolvidas no bloco, no qual se insere o Brasil.

Segundo Jank e Nassar (2005), o setor agroalimentar tem papel estratégico nas economias do MERCOSUL, tanto pela situação atual 
quanto pelas possibilidades de ampliação de suas fronteiras físicas e tecnológicas. Principalmente no Brasil, na Argentina e no Uruguai, o setor de carne bovina tem participação relevante no agronegócio desses países, os quais também são responsáveis por importante parcela do comércio mundial do setor. De acordo com a FAO, 206 países são produtores de carne bovina no mundo, e, no ano de 2004, o Brasil foi o segundo maior produtor mundial, responsável por 13,1\%, ficando atrás apenas dos Estados Unidos, que detinham 19\%. A Argentina ocupou a quarta posição, sendo responsável por 4,5\% do total mundial.

Quanto às exportações de carne bovina, as informações da FAO indicam que 162 países exportam o produto, sendo que, em 2004, aproximadamente metade da exportação mundial foi proveniente do Brasil (17,7\%), Austrália (15,6\%), Canadá (6,9\%), Alemanha (5,5\%) e Estados Unidos (2,5\%). A Austrália, principal exportador de carne bovina no período 1990-2003, manteve a sua participação até 2001, que, a partir desse ano, começou a cair, tendo o Brasil alcançado o primeiro lugar em 2004. A China, que ocupa o terceiro lugar na produção mundial de carne bovina, não está entre os principais países exportadores desse produto, o que indica que não necessariamente os maiores produtores são também os maiores exportadores do produto, razão da relevância do mercado consumidor interno.

Os países que importam carne bovina são 203. No ano de 2004, aproximadamente metade das importações mundiais foi para os Estados Unidos (20,2\%), Rússia (7,9\%), Japão (7,6\%), Itália (5,8\%) e México $(3,6 \%)$, e os demais países importaram a metade restante (FAO, 2006). Os Estados Unidos, além de estar entre os principais produtores e exportadores, também ocupa o primeiro lugar nas importações mundiais de carne bovina, diferentemente do Brasil, que se configura como primeiro e segundo lugar na exportação e produção de carne bovina, respectivamente.

Como mencionado anteriormente, no comércio internacional de produtos agrícolas as restrições comerciais são relevantes e podem ser de natureza 
tarifária ou não-tarifária (como, por exemplo, sanitárias). São discutidas por diversos autores, dentre eles, Ferreira e Vieira (2005), Kume et al. (2004) e Thorstensen e Jank (2005). Para o setor de carne bovina, essas medidas são também relevantes, visto que restringem mercados. Miranda (2001) enfatizou que as políticas tradicionais, como tarifas e cotas, são restritivas e importantes, razão pela qual devem ser consideradas quando se trata do comércio internacional de carne bovina.

Fabiosa et al. (2005), ao estudarem os efeitos do comércio e políticas agrícolas nos fluxos comerciais mundiais, focalizaram os países em desenvolvimento, inclusive os do MERCOSUL. Segundo esses autores, com a remoção de distorções na agricultura, a maioria dos preços mundiais aumentaria; os preços de laticínios, carnes, açúcar e óleos elevariam muito; e os de trigo e milho subiriam de forma moderada. Expansões significativas na produção agrícola ocorrem nos países em desenvolvimento que são exportadores naturais, tais como Brasil, Argentina e Tailândia, e também nos países ricos, como Austrália, Nova Zelândia e Estados Unidos. Muitas economias em desenvolvimento aproveitam as oportunidades de expansão em mercados agrícolas de valor agregado, a exemplo da produção e exportação de carne bovina e de frango.

Nesse contexto, o objetivo deste artigo é analisar as perspectivas de produção, exportações, importações, preços e níveis de bem-estar para o setor de carne bovina no MERCOSUL, em frente a cenários de redução tarifária em nível multilateral e de um acordo entre o bloco e a União Européia. Dessa forma, podem ser avaliados os possíveis efeitos sobre consumidores e produtores do bloco, caso haja liberalização multilateral junto à $\mathrm{OMC}$ ou se concretize o acordo de livre comércio entre MERCOSUL e União Européia. A seguir, é apresentado o método usado para atingir o objetivo proposto (seção 2), bem como os resultados e as considerações finais, que estão nas seções 3 e 4, respectivamente. 


\section{Método}

Para analisar as perspectivas de produção, exportações, importações, preços e níveis de bem-estar para o setor de carne bovina no MERCOSUL, em face de cenários de redução tarifária, em nível multilateral, algumas etapas foram necessárias.

A partir das funções de oferta e demanda de carne bovina, dos custos de transporte entre as regiões e das restrições comerciais é construído o cenário atual do comércio internacional de carne bovina, no qual serão obtidos a quantidade produzida e consumida e os preços de carne bovina em cada região estudada. A partir do cenário atual são simuladas diferentes políticas comerciais no âmbito multilateral (redução tarifária) e regional (eliminação das tarifas de importação entre MERCOSUL e UE), obtendo-se, para as novas situações, novas quantidades e preços de equilíbrio.

Para construir o cenário atual e as simulações, o modelo utilizado neste trabalho é estático, espacial e de equilíbrio parcial. É estático porque estima o equilíbrio em um ponto do processo de ajustamento A característica espacial refere-se à alocação, que é considerada nos custos de transporte; e é de equilíbrio parcial porque considera o mercado de carne bovina. Na análise admite-se que os demais mercados não sofram alterações durante o processo de ajustamento.

De acordo com Alvim e Waquil (2004), esse método visa solucionar o problema de comércio entre diferentes regiões que apresentam ofertas, demandas e fluxos comerciais distintos. Segundo Waquil (1995), o primeiro a introduzir o conceito de equilíbrio espacial foi Samuelson (1952), por meio de uma representação formal do problema a partir da otimização de uma função Net Social Payoff (NSP) ${ }^{3}$. Dessa forma, o conceito de NSP é fundamental para compreensão do processo de otimização que

Essa função corresponde à soma dos excedentes dos consumidores e dos produtores, ou seja, à soma do bemestar dos consumidores e dos produtores. 
conduz aos resultados no equilíbrio de mercado, onde são obtidos as quantidades, os fluxos comerciais e os preços.

A análise de equilíbrio parcial trata do equilíbrio de mercado para certo produto e considera-se que os agentes (produtores e consumidores) agem de forma eficiente. Do resultado desse processo simultâneo de maximização obtêm-se os preços e as quantidades de equilíbrio que correspondem à situação de bem-estar máximo em determinado mercado. Para medir as variações no bem-estar social utilizam-se os conceitos de excedente do consumidor, do produtor e o excedente total, quando ocorrem mudanças que alteram os preços e as quantidades de equilíbrio.

O equilíbrio de mercado é obtido por meio da maximização da função NSP, que consiste na soma do excedente do consumidor e do produtor menos o custo de transporte entre a região de produção e de consumo (Samuelson apud Waquil, 1995).

Baseado no problema de otimização (NSP) com restrições na forma de desigualdades, Alvim (2003) apresentou o Problema de Complementaridade Mista (PCM), em que uma das vantagens dessa formulação é facilitar a inclusão de tarifas no modelo. Dessa forma, o PCM permite simular, diretamente, mudanças de ordem política que operam sobre os preços de mercado, como, por exemplo, as restrições tarifárias. Segundo esse autor, no PCM as equações podem ter igualdades e desigualdades, sendo que a idéia central da formulação deste problema parte das funções de demanda e oferta e das condições de Kuhn-Tucker. A formulação do Modelo de Alocação Espacial, como um Problema de Complementaridade Mista, é apresentada a seguir:

$$
\sum_{j}^{J} X_{i, j} \leq q_{i}^{s} \quad \varphi_{i} \geq 0, \quad\left(\sum_{j}^{J} X_{i, j}-q_{i}^{s}\right) \cdot \varphi_{i}=0, \forall i, j
$$




$$
\begin{aligned}
& q_{j}^{d} \leq \sum_{i}^{I} X_{i, j} \quad \lambda_{j} \geq 0, \quad\left(q_{j}^{d}-\sum_{i}^{I} X_{i, j}\right) \cdot \lambda_{j}=0, \forall_{i, j} \\
& \lambda_{j} \leq \varphi_{i}+t_{i, j} \quad X_{i, j} \geq 0 \quad\left(\lambda_{j}-\varphi_{i}-t_{i, j}\right) \cdot X_{i, j}=0, \forall i, j
\end{aligned}
$$

em que

$i, j$ são as regiões;

$q_{j}^{d}$ é a quantidade consumida na j-ésima região;

$q_{i}^{s}$ é a quantidade produzida na i-ésima região;

$X_{i, j}$ é a quantidade de produto comercializada entre a região i e j;

$t_{i, j}$ é o custo de transporte entre as regiões i e $\mathrm{j}$;

$\lambda_{j}$ é o preço-sombra do produto consumido na j-ésima região;

$\varphi_{i}$ é o preço-sombra do produto produzido na i-ésima região.

As três equações $(2.1,2.2$ e 2.3$)$ correspondem ao PCM e representam as condições que permitem obter os preços-sombra ${ }^{4}$, as quantidades consumidas e produzidas e o fluxo comercial entre as regiões. O PCM permite delimitar o conjunto de soluções do problema, cujo resultado final é obtido na medida em que as condições representadas pelas três equações forem obedecidas.

\footnotetext{
Preço máximo que o consumidor está disposto a pagar por uma unidade adicional de produto; para o produtor, é o preço mínimo que está disposto a receber para produzir uma unidade adicional de produto.
} 
De acordo com Alvim e Waquil (2004), como os preços-sombra são apresentados de maneira explícita, podem-se incluir diretamente nos preços as variáveis como tarifas, quotas-tarifárias e subsídios. Dessa forma, o modelo é usado para medir impactos de medidas políticas no mercado, neste caso, no de carne bovina, tais como os acordos comerciais.

Para operacionalizar o Problema de Complementaridade Mista foi usado o software GAMS (General Algebraic Modeling System). Neste estudo, todos os países do mundo foram agrupados em onze regiões, descritas a seguir, no Quadro 1. As regiões foram determinadas principalmente de acordo com os blocos econômicos, sendo o continente africano considerado uma região, em razão de os blocos daquele continente não serem expressivos quanto ao produto em estudo, e China e Japão, devido à relevância desses países no contexto internacional. A União Européia atualmente é composta por 27 países, no entanto, o estudo considera apenas os 25 primeiros integrantes (Alemanha, Áustria, Bélgica, Chipre, Dinamarca, Eslováquia, Eslovênia, Espanha, Estônia, Finlândia, França, Grécia, Hungria, Irlanda, Itália, Letônia, Lituânia, Luxemburgo, Malta, Países Baixos, Polônia, Portugal, Reino Unido, República Tcheca e Suécia). 
Quadro 1 - Regiões consideradas no estudo

\begin{tabular}{|c|l|}
\hline REGIÕES & \multicolumn{1}{|c|}{ PAÍSES } \\
\hline MER & Mercado Comum do Sul (MERCOSUL) \\
\hline UE & União Européia (25 países que compõem o bloco) \\
\hline NAF & North American Free Trade Agreement (NAFTA) \\
\hline OCE & Oceania \\
\hline ASC & América do Sul e Central exceto o MERCOSUL \\
\hline ASE & ASEAN (Association of South East Asian Nations ) \\
\hline AFR & Continente Africano \\
\hline CHI & China \\
\hline JAP & Japão \\
\hline CEI & Comunidade dos Estados Independentes \\
\hline RM & Resto do Mundo (países que não foram contemplados nas demais regiões) \\
\hline
\end{tabular}

Fonte: Elaboração própria.

Os valores das variáveis usadas para estimar as funções de oferta e demanda do modelo - produção, exportação, importação, consumo e preços - foram agregados conforme as regiões apresentadas e obtidos da base de dados da Food and Agriculture Organization (FAO). Na base de dados da FAO, sob a denominação bovine meat, foram obtidas produção, exportação e importação em toneladas e em dólares por toneladas. Foi feita a média aritmética dos últimos três anos disponíveis (2002, 2003 e 2004), a fim de evitar a influência de um possível evento atípico ocorrido em determinada região, em algum ano. O consumo aparente e os preços foram estimados a partir dessas informações da FAO.

As elasticidades-preço da oferta e da demanda de cada região, também usadas para estimação das funções de oferta e demanda, foram obtidas de Sullivan et al. (1992). Os custos de transporte e as tarifas de importação entre as regiões foram obtidos, respectivamente, do Frigorífico Mercosul (Bagé/RS) e do United States Department of Agriculture (USDA). 
Na próxima seção são apresentados e discutidos o cenário atual de carne bovina e os cenários de redução tarifária, em nível multilateral, do acordo de livre comércio entre o MERCOSUL e a UE, bem como o de livre comércio multilateral.

\section{O cenário atual e os cenários alternativos}

Como o propósito do trabalho é enfatizar os efeitos de acordos comerciais no setor de carne bovina do MERCOSUL, os comentários são direcionados aos resultados para produtores, consumidores e sociedade como um todo, no bloco. No entanto, os resultados obtidos permitem analisar os efeitos da redução tarifária especificamente para cada uma das onze regiões consideradas.

\subsection{Resultados e discussão}

Nesta seção são apresentados e discutidos os resultados obtidos para o cenário atual do mercado mundial de carne bovina (3.1.1), de tarifas reduzidas à metade (3.1.2), do acordo de livre comércio entre o MERCOSUL e a UE (3.1.3) e de livre comércio multilateral (3.1.4).

\subsubsection{O cenário atual}

Os resultados do cenário atual de produção, consumo e preços de carne bovina nas onze regiões, obtidos por meio do Modelo de Alocação Espacial, foram comparados com os dados observados na base de dados da FAO, sendo os valores bastante próximos, o que permite a validação do modelo para construção dos cenários. Além desses resultados, o modelo traz informações a respeito dos fluxos comerciais entre as regiões determinadas, sendo também analisadas no cenário atual e comparadas com os demais cenários nas próximas seções. Então, na Tabela 1, estão 
os resultados do cenário atual de carne bovina, obtido a partir do Modelo de Alocação Espacial.

Os principais produtores de carne bovina, atualmente, são os blocos NAFTA e MERCOSUL. O NAFTA ocupa o primeiro lugar na produção de carne bovina, com 14.434.650 ton., seguido por MERCOSUL, que produz 10.919.830 ton. Dentre as demais regiões, UE, América do Sul e Central, ASEAN, África, China, Japão, CEI e Resto do Mundo produzem para consumo próprio, bem como também o NAFTA. No cenário atual, apenas MERCOSUL e Oceania são regiões exportadoras líquidas. O MERCOSUL comercializa carne bovina com NAFTA e CEI, sendo as quantidades, respectivamente, de 1.583 .886 e 463.939 toneladas. A Oceania vende para ASEAN, China e Japão, respectivamente, 229.275, 271.572 e 857.255 toneladas.

Tabela 1 - O cenário atual de carne bovina

\begin{tabular}{cccccccccccc}
\hline VARIÁVEIS/REGIÕES & MER & UE & NAF & OCE & ASC & ASE & AFR & CHI & JAP & CEI & RM \\
\hline Produção (ton) & 10.919 .830 & 8.031 .865 & 14.434 .650 & 2.478 .539 & 2.441 .448 & 1.078 .057 & 4.256 .406 & 5.937 .281 & 487.701 & 3.731 .872 & 4.553 .761 \\
Consumo (ton) & 8.872 .000 & 8.031 .865 & 16.018 .540 & 1.120 .436 & 2.441 .448 & 1.307 .333 & 4.256 .406 & 6.208 .854 & 1.344 .957 & 4.195 .812 & 4.553 .761 \\
Preço (US\$/ton) & $1.643,10$ & $2.940,70$ & $2.293,10$ & $1.508,10$ & $1.782,80$ & $1.876,80$ & $1.872,00$ & $2.170,20$ & $2.446,00$ & $1.824,40$ & $1.919,70$ \\
EP (US\$ milhōes) & $17.686,5$ & $21.489,3$ & $36.073,3$ & $3.518,4$ & $4.508,8$ & $1.963,2$ & $9.168,5$ & $31.587,2$ & $1.629,1$ & $13.289,0$ & $10.399,6$ \\
EC (US\$ milhōes) & $10.856,9$ & $16.923,1$ & $22.675,3$ & $1.573,2$ & $2.614,3$ & $2.284,9$ & $7.755,6$ & $8.994,4$ & $2.163,8$ & $19.346,0$ & $5.386,2$ \\
ET (US\$ milhões) & $28.543,4$ & $38.412,4$ & $58.748,6$ & $5.091,6$ & $7.123,2$ & $4.248,1$ & $16.924,1$ & $40.581,6$ & $3.792,9$ & $32.635,0$ & $15.785,8$ \\
\hline
\end{tabular}

Fonte: Resultados da pesquisa.

Legenda: MER = MERCOSUL; UE = União Européia; NAF = NAFTA; OCE = Oceania; ASC = América do Sul e Central exceto o MERCOSUL; ASE = ASEAN; $\mathrm{CHI}=$ China; JAP = Japão; CEI = Comunidade dos Estados Independentes; RM $=$ Resto do Mundo.

O NAFTA também ocupa a primeira posição no consumo de carne bovina, que é de 16.018.540 toneladas, necessidade suprida pelas importações originárias do MERCOSUL, já mencionadas. O segundo maior consumidor é o MERCOSUL e o terceiro, a EU, que consomem, respectivamente, 8.872 .000 e 8.031 .865 toneladas. 
Os preços mais elevados de carne bovina encontram-se na UE e no Japão, US\$ 2.940/ton e US\$2.446/ton, respectivamente e os menores na Oceania e no MERCOSUL, US\$ $1.508 /$ ton e US\$ $1.643 /$ ton, respectivamente, em virtude de estas serem regiões produzirem para seu consumo próprio e de serem exportadoras líquidas, o que reflete suas vantagens comparativas na produção de carne bovina. O mesmo não ocorre com a UE, que, apesar de produzir o necessário para seu consumo interno, apresenta o maior preço de carne bovina, decorrente de subsídios e de sua desvantagem comparativa na produção.

\subsubsection{O cenário de tarifas reduzidas à metade}

Neste cenário, apresentam-se os efeitos de uma situação de redução tarifária multilateral à metade, ou seja, as tarifas de importação de carne bovina das onze regiões em estudo passam a ser metade do que são no cenário atual. A Tabela 2 apresenta as variações que ocorrem neste cenário, em relação ao cenário atual.

Tabela 2 - Variação dos resultados de Tarifas pela Metade em relação ao Cenário Atual (em \%)

\begin{tabular}{lrrrrrrrrrrr}
\hline VARI ÁVEI S/REG IÕES & MER & UE & NAF & OCE & ASC & ASE & AFR & CHI & JAP & CEI & RM \\
\hline Produção & 5,1 & $-4,5$ & $-1,5$ & 6,2 & 1,5 & 1,5 & 0,6 & $-0,6$ & $-2,8$ & 2,2 & 0,0 \\
Consumo & $-6,7$ & 5,7 & 2,6 & $-6,3$ & $-2,5$ & $-1,6$ & $-0,7$ & 2,2 & 5,8 & $-1,7$ & 0,0 \\
Preços & 10,0 & $-8,1$ & $-3,3$ & 11,7 & 3,0 & 2,9 & 1,4 & $-2,9$ & $-7,7$ & 8,6 & 0,0 \\
EP & 10,4 & $-8,7$ & $-3,0$ & 12,8 & 3,0 & 3,0 & 1,2 & $-1,2$ & $-5,5$ & 4,5 & 0,0 \\
EC & $-12,9$ & 11,7 & 5,4 & $-12,1$ & $-5,0$ & $-3,1$ & $-1,4$ & 4,4 & 12,0 & $-3,4$ & 0,0 \\
ET & 1,5 & 0,3 & 0,2 & 5,1 & 0,0 & $-0,3$ & 0,0 & 0,1 & 4,5 & $-0,2$ & 0,0 \\
\hline
\end{tabular}

Fonte: Resultados da pesquisa.

Legenda: MER $=$ MERCOSUL $;$ UE $=$ União Européia NAF $=$ NAFTA $;$ OCE $=$ Oceania; ASC = América do Sul e Central exceto o MERCOSUL; ASE = ASEAN; $\mathrm{CHI}=\mathrm{China} ; \mathrm{JAP}=\mathrm{Japão} ; \mathrm{CEI}=$ Comunidade dos Estados Independentes; $\mathrm{RM}$ $=$ Resto do Mundo. 
Observa-se que no MERCOSUL a produção aumenta 5,1\%, passando para 11.472.040 ton., e, mesmo assim, os preços aumentam em 10\%. Isso ocorre porque aumentam as exportações de carne bovina do MERCOSUL para o NAFTA, e o MERCOSUL passa a exportar para a UE. O incremento nas exportações deve-se à redução tarifária nessas duas regiões, embora o mesmo não ocorra nos fluxos do MERCOSUL para CEI, visto que a tarifa de importação desta região já era muito baixa $(0,8 \%)$ e a redução à metade não estimulou o aumento de exportações para essa região, havendo redução das exportações quase pela metade, em relação ao cenário atual. Dessa forma, constata-se que, com a redução tarifária pela metade, as exportações de carne bovina do MERCOSUL são redirecionadas para a UE e incrementadas para o NAFTA, e CEI perde participação no total.

A produção e os preços diminuem na UE, enquanto NAFTA, China e Japão acompanham a mesma tendência (Tabela 2). Isso ocorre por causa do aumento de exportações para essas regiões, onde parte da produção doméstica é substituída, em maior quantidade, pelas importações (pois as tarifas foram reduzidas à metade), o que proporciona maior oferta de carne bovina em seus mercados internos e reduzindo os preços para os consumidores. Assim, nessas regiões, os níveis de bem-estar dos consumidores (EC) são incrementados, respectivamente, em 11,7\%, 5,4\%, $4,4 \%$ e $12 \%$. Em relação aos níveis de bem-estar dos produtores (EP), nessas regiões constata-se redução, devido à diminuição da produção interna e da queda dos preços. No entanto, quando se analisa o excedente total (ET), nota-se que há aumento nos níveis de bem-estar agregado, o que indica que a redução das tarifas foi benéfica quando se analisa o bem-estar de consumidores e produtores, em conjunto.

Os efeitos nos níveis de bem-estar dos diferentes agentes no MERCOSUL são diferentes dos da UE, NAFTA, China e Japão, e são semelhantes aos da Oceania. No cenário atual, MERCOSUL e Oceania são exportadores líquidos de carne bovina, e, quando as tarifas de importação são reduzidas à metade, essas regiões aumentam sua produção e reduzem o consumo interno para aumentar seus fluxos de comércio 
para outras regiões (Tabela 2). Dessa forma, ocorrem elevações de 10\% e 11,7\% nos preços, no MERCOSUL e na Oceania, respectivamente. Como era de esperar, há redução no nível de bem-estar dos consumidores (EC), nas duas regiões, e aumento no nível de bem-estar dos produtores (EP), pois os primeiros passam a consumir menos carne bovina e pagam um preço mais alto, por isso, os últimos passam a produzir mais para a exportação, a um preço elevado, ou seja, o aumento do nível de bemestar dos produtores compensou a redução do nível de bem-estar dos consumidores, sendo o nível de bem-estar agregado com redução das tarifas à metade superior ao cenário atual, 1,5\% para o MERCOSUL e $5,1 \%$ para a Oceania.

Nas regiões América do Sul e Central, ASEAN, África e CEI, os efeitos sobre produção e consumo não foram significativos, quando as tarifas foram reduzidas à metade. Quando se consideram os preços, na CEI há elevação de 8,6\%, possivelmente causada pela redução das exportações do MERCOSUL para essa região, como já comentado no início desta seção. Então, assim como ocorre na América do Sul e Central, ASEAN e África, no MERCOSUL o nível de bem-estar dos produtores (EP) apresenta incrementos e o nível de bem-estar dos consumidores (EC), redução. No entanto, o nível de bem-estar agregado (ET) não apresenta variação significativa nessas regiões.

Diante dos resultados, constata-se que em todas as regiões, à exceção de ASEAN e CEI, a redução das tarifas trouxe benefícios à população. No entanto, alguns agentes, produtores ou consumidores, dependendo da região, foram prejudicados. Por exemplo, no caso dos consumidores, estes foram prejudicados em algumas regiões, visto que o preço aumentou e a quantidade disponível para consumo no mercado interno foi reduzida. Os consumidores pagariam mais caro pela carne bovina, se a redução tarifária também ocorresse para outros produtos; a região teria vantagens comparativas na produção; e poderia haver compensação para os consumidores. 


\subsubsection{O Cenário de Livre Comércio MERCOSUL-UE}

Esta seção apresenta a simulação de um acordo de livre comércio entre o MERCOSUL e a União Européia, sendo apresentados os efeitos da eliminação das tarifas de importação de carne bovina entre os dois blocos. A seguir, a Tabela 3 mostra os resultados obtidos.

Tabela 3 - Variação dos resultados do Acordo de Livre Comércio MERCOSUL-UE em relação ao Cenário Atual (em \%)

\begin{tabular}{lccccccccccc}
\hline \multicolumn{1}{c}{ VARI ÁVEIS/REGIÕES } & MER & UE & NAF & OCE & ASC & ASE & AFR & CHI & JAP & CEI & RM \\
\hline Produção & 5,7 & $-18,3$ & 3,1 & 3,8 & 0,3 & 3,5 & 0 & 0,9 & 2,4 & 1,6 & 0 \\
Consumo & $-7,5$ & 23,2 & $-5,5$ & $-3,9$ & $-0,5$ & $-3,6$ & 0 & $-3,5$ & $-5,1$ & $-1,3$ & 0 \\
Preço & 11,2 & $-33,3$ & 6,8 & 7,2 & 0,6 & 6,8 & 0 & 4,6 & 6,7 & 6,4 & 0 \\
EP & 11,7 & $-33,2$ & 6,4 & 7,8 & 0,6 & 7,1 & 0 & 1,9 & 4,9 & 3,3 & 0 \\
EC & $-14,5$ & 51,8 & $-1,9$ & $-7,6$ & -1 & $-7,1$ & 0 & $-6,8$ & $-9,9$ & $-2,5$ & 0 \\
ET & 1,7 & 4,2 & 3,2 & 3 & 0 & $-0,6$ & 0 & 0 & $-3,5$ & $-0,1$ & 0 \\
\hline
\end{tabular}

Fonte: Resultados da pesquisa.

Legenda: MER = MERCOSUL; UE = União Européia; NAF = NAFTA; OCE = Oceania; ASC = América do Sul e Central exceto o MERCOSUL; ASE = ASEAN; $\mathrm{CHI}=$ China; JAP = Japão; CEI = Comunidade dos Estados Independentes; RM $=$ Resto do Mundo.

Neste cenário, a produção e os preços de carne bovina aumentam ou permanecem os mesmos em todas as regiões, exceto para a UE, que apresenta redução de 18,3\% e 33,3\% nessas variáveis, respectivamente. No que se refere ao consumo, é na UE que este aumenta na medida de, aproximadamente, $23 \%$ em relação ao do cenário atual.

Na América do Sul e Central, África, China e CEI, o acordo de livre comércio entre o MERCOSUL-UE, no setor de carne bovina, não traz efeitos significativos. No entanto, além dos dois blocos envolvidos, os efeitos são também significativos sobre o NAFTA e sobre a Oceania, regiões onde a produção e também a exportação de carne bovina são relevantes no cenário atual. 
Pode-se notar que a produção no MERCOSUL aumenta o equivalente a $5,7 \%$, em relação ao cenário atual (que corresponde a 11.539.180 ton.), e o seu consumo é reduzido em 7,5\%, visto que exporta para a UE a quantidade de 3.333.199 toneladas de carne bovina, deixando de exportar para as demais regiões, como NAFTA e CEI (no cenário atual). Embora a produção e o consumo de carne bovina no MERCOSUL sejam reduzidos, o preço eleva-se em torno de $11 \%$, justamente em virtude do aumento das vendas para a UE. Nesse sentido, o nível de bem-estar dos consumidores apresenta redução, o que indica que esses agentes são prejudicados, e medidas compensatórias são necessárias, caso este acordo entre em vigor.

Na UE, a relação inverte-se, ou seja, são os produtores que têm as maiores perdas com o acordo, visto que a quantidade produzida internamente se reduz (passa a ser de 6.563.379 ton., que correspondem a dois terços do consumo total do bloco), mesmo com o aumento no consumo, que é suprido pelas importações provenientes do MERCOSUL, a um preço inferior ao do cenário atual, conforme já mencionado no início da seção.

Os efeitos do acordo sobre o NAFTA e sobre a Oceania são semelhantes ao que ocorreria no MERCOSUL. A Oceania passaria a suprir a demanda de carne bovina em regiões onde o último atenderia, como, por exemplo, o NAFTA, e também exportaria para ASEAN, Japão e CEI.

Quando se analisa o nível de bem-estar total (ET), para MERCOSUL e EU, constata-se que ambos são elevados, o que indica que, quando se analisam os efeitos sobre os agentes (produtores e consumidores), há ganhos decorrentes do acordo, embora se deva atentar para mecanismos compensatórios para os agentes prejudicados em cada região, como os consumidores no MERCOSUL e os produtores na UE. 


\subsubsection{Livre Comércio Multilateral}

Neste cenário, são apresentados os efeitos de um acordo de liberalização multilateral para o setor de carne bovina, no âmbito da OMC, sendo removidas todas as tarifas de importação que existem no cenário atual. São considerados os custos de transporte entre as regiões como diferenciais de preços entre elas.

A seguir, a Tabela 4 apresenta os efeitos da liberalização do comércio de carne bovina em relação ao cenário atual. É neste cenário de livre comércio multilateral que o MERCOSUL produz a maior quantidade de carne bovina, que é de 12.153.790 ton. (incremento de 11,3\%). No entanto, este também é o cenário onde a quantidade consumida é a menor e os preços apresentam o maior incremento, $22 \%$ em relação ao do cenário atual, atingindo o valor de US\$2,009/ton. Dessa forma, constata-se que a variação no nível de bem-estar dos produtores é maior neste cenário, em relação aos discutidos anteriormente. A respeito do nível de bemestar dos consumidores do MERCOSUL, este cenário apresenta redução em torno de $28 \%$, mas, se for considerado o nível de bem-estar agregado para a população como um todo, é superior em $4,2 \%$ ao nível do cenário atual. Apesar dessa redução no bem-estar dos consumidores, há aumento no nível de bem-estar agregado, e serão relevantes políticas públicas compensatórias para os agentes que são prejudicados (neste caso, os consumidores da região), se o acordo de liberalização em âmbito multilateral entrar em vigor. 
Tabela 4 - Variação dos resultados de Livre Comércio em relação ao Cenário Atual (em \%)

\begin{tabular}{lrrrrrrrrrrr}
\hline VARI ÁVEI S/REG IÕES & MER & UE & NAF & OCE & ASC & ASE & AFR & CHI & JAP & CEI & RM \\
\hline Produção & 11,3 & $-14,9$ & $-3,2$ & 13,9 & 6,9 & 3,3 & 5,3 & $-1,3$ & $-6,3$ & 4,8 & 1,7 \\
Consumo & $-15,0$ & 18,9 & 5,7 & $-14,0$ & $-12,0$ & $-3,5$ & $-6,3$ & 4,8 & 13,1 & $-3,7$ & $-3,3$ \\
Preços & 22,3 & $-27,1$ & $-7,0$ & 26,1 & 14,4 & 6,4 & 12,2 & $-6,4$ & $-17,2$ & 18,9 & 4,1 \\
EP & 23,9 & $-27,5$ & $-6,3$ & 29,7 & 14,4 & 6,8 & 10,9 & $-2,6$ & $-12,2$ & 9,9 & 3,5 \\
EC & $-27,7$ & 41,3 & 11,7 & $-26,1$ & $-22,5$ & $-6,8$ & $-12,1$ & 9,8 & 27,9 & $-7,3$ & $-6,6$ \\
ET & 4,3 & 2,8 & 0,6 & 12,4 & 0,8 & $-0,5$ & 0,3 & 0,2 & 10,7 & $-0,3$ & 0,1 \\
\hline
\end{tabular}

Fonte: Resultados da pesquisa.

Legenda: MER = MERCOSUL; UE = União Européia; NAF = NAFTA; OCE = Oceania; ASC = América do Sul e Central exceto o MERCOSUL; ASE = ASEAN; $\mathrm{CHI}=$ China; JAP = Japão; CEI = Comunidade dos Estados Independentes; RM $=$ Resto do Mundo.

Oceania e Japão são as regiões que apresentam maiores incrementos no bem-estar agregado, que são de $12,4 \%$ e $10,7 \%$, respectivamente. No entanto, os agentes que são beneficiados nessas duas regiões são diferentes, ou seja, na Oceania, o nível de bem-estar dos produtores aumenta em torno de $30 \%$ e, no Japão, é o nível de bem-estar dos consumidores que apresenta incremento de, aproximadamente, $28 \%$. Assim, as políticas públicas devem ser voltadas para os consumidores da Oceania, que são prejudicados pela elevação do preço em sua região e pela redução da quantidade consumida de carne bovina. Para os produtores do Japão, a redução dos preços e da quantidade produzida, em virtude do aumento das exportações para essa região (principalmente da Oceania e da China), faz com que o nível de bem-estar seja reduzido em $12,2 \%$, em relação ao cenário atual, e que necessitem de um auxílio compensatório.

Sob livre comércio, NAFTA e China apresentam redução na quantidade produzida de $3,2 \%$ e $1,3 \%$, respectivamente. Já o consumo é incrementado nas duas regiões em torno de $5 \%$, como se pode observar na Tabela 4, visto que os preços diminuem $7 \%$ e $6,4 \%$, respectivamente. Isso é possível devido ao aumento das exportações para essas regiões, já que, em relação ao cenário atual, elas agora são superiores e provenientes, basicamente, do MERCOSUL (no caso do NAFTA) e da 
Oceania (no caso da China). Dessa forma, o nível de bem-estar dos produtores apresenta redução, enquanto o dos consumidores é incrementado em relação ao cenário atual. Quando se analisa o nível de bem-estar agregado, nota-se pequena elevação.

As regiões América do Sul e Central, ASEAN, África e CEI apresentam incremento na produção, neste cenário de livre comércio multilateral, respectivamente, de $6,9 \%, 3,3 \%, 5,3 \%$ e $4,8 \%$ em relação ao cenário atual. Já os preços são incrementados, e o consumo apresenta redução nas quatro regiões em análise. Assim, o nível de bem-estar dos produtores (EP) melhora nessas regiões, e o nível de bem-estar dos consumidores (EC) é reduzido nas mesmas quatro regiões, visto que os preços se elevam e as quantidades consumidas se reduzem. Quanto ao nível de bem-estar agregado (ET) da população, observa-se que há pequena variação, o que sinaliza que, quando se considera a população como um todo nessas regiões, não existem benefícios significativos neste cenário de livre comércio.

\section{Considerações Finais}

No contexto do comércio internacional de carne bovina, a exemplo de outros produtos alimentícios, destaca-se a importância do aumento da imposição de restrições comerciais por parte dos países e, ou, regiões, tanto tarifárias quanto não-tarifárias, tais como as fitossanitárias. Isso decorre da questão de segurança alimentar ou da proteção que os governos concedem aos produtores de certas regiões. Então, cada vez mais são exigidos requisitos para exportação, com o objetivo de efetuar uma padronização mínima que garanta a segurança alimentar, podendose afirmar que a rastreabilidade é uma importante exigência para com a exportação.

Neste artigo, foram analisados quatro cenários do comércio internacional de carne bovina para onze regiões estudadas, sendo o primeiro deles o cenário atual, seguido pelos cenários de tarifas reduzidas à metade, acordo 
de livre comércio MERCOSUL-UE e, por fim, o de livre comércio multilateral. No cenário atual, as regiões MERCOSUL e Oceania são exportadoras líquidas e as demais produzem para consumo interno e, dentre estas, algumas são importadoras (NAFTA, ASEAN, China, Japão e CEI). Quando se analisa o nível de bem-estar dos produtores do MERCOSUL, o livre comércio é o cenário que mais traz benefícios a esses agentes. A segunda melhor opção para os produtores de carne bovina no MERCOSUL seria o cenário de tarifas reduzidas à metade, seguido pelo acordo de livre comércio MERCOSUL-UE. No entanto, os cenários de redução de tarifas à metade e de livre comércio para MERCOSUL-UE apresentam efeitos muito semelhantes, podendo-se considerar aqueles para o MERCOSUL como equivalentes, embora não se possa afirmar o mesmo para a UE.

Quanto ao nível de bem-estar de todos os agentes no MERCOSUL (produtores e consumidores), denominado excedente total ou ET, este se encontra na mesma direção que o nível de bem-estar dos produtores. Já o nível de bem-estar dos consumidores no MERCOSUL, no cenário de livre comércio multilateral, apresenta significativa redução em relação ao cenário atual, ou seja, segue na direção oposta ao aumento no nível de bem-estar dos produtores da região. Isso pode ser explicado pelo fato de que, com o livre comércio multilateral, o bloco passa a produzir e exportar mais carne bovina, a um preço mais elevado, do que no cenário atual (em virtude da redução das tarifas). Dessa forma, os consumidores passam a ter menores quantidades disponíveis internamente, a preço mais elevado, visto que o mercado mundial está aberto ao bloco e disposto a pagar um preço mais elevado pelo produto.

Nesse sentido, os resultados obtidos podem contribuir para que sejam formuladas políticas públicas para o setor de carne bovina no MERCOSUL, visto que apresenta os impactos que três diferentes níveis de liberalização comercial trariam no setor de carne bovina no bloco, destacando as perdas e os ganhos dos consumidores e produtores. Assim, podem ser identificados os agentes que teriam prejuízo com a liberalização do comércio desse produto, podendo-se direcionar ações compensatórias 
a eles, caso algum desses acordos entre em vigor.

Por fim, outros cenários de interesse devem ser estudados, com vistas em superar algumas limitações, tais como homogeneidade do produto, bem como somente os custos de transporte marítimos entre cada porto das onze regiões analisadas. Além disso, todos os países foram agregados em onze grandes regiões para estimar oferta e demanda, no entanto, as condições internas de cada um podem ser diferentes. Nesse sentido, o modelo expressa uma simplificação da realidade, que possibilita estimar impactos de acordos comerciais em determinado setor. Diante disso, sugerem-se pesquisas futuras que contemplem os impactos dos acordos comerciais sobre no setor de carne bovina no MERCOSUL e também no Brasil, separadamente; a inclusão de maior número de regiões; a incorporação dos custos de transporte dos portos nos mercados consumidores; diferenciação de produto (tais como carne bovina in natura e industrializada); dentre outras características.

\section{Referências}

ALVIM, Augusto Mussi. Os impactos dos novos acordos de livre comércio sobre o mercado de arroz no Brasil: um modelo de alocação espacial e temporal. 2003. 221 f. Tese (Doutorado) Universidade Federal do Rio Grande do Sul. Faculdade de Ciências Econômicas. Programa de Pós-Graduação em Economia. Porto Alegre, 2003.

ALVIM, Augusto Mussi; WAQUIL, Paulo Dabdab. O problema de complementaridade mista: um modelo de alocação espacial aplicado ao setor agrícola. In: VIEIRA, Wilson da Cruz; SANTOS, Maurinho Luiz dos. Métodos quantitativos em economia. Viçosa: Editora UFV, 2004.

FABIOSA, Jay et al. The Doha round of the World Trade Organization and agricultural markets liberalization: impacts on developing economies. Review of Agricultural Economics, v. 27, n. 3, p. 317-335, Sept. 2005. 
FERREIRA, Gabriela Cardozo; VIEIRA, Luciana Marques. Traceability in Brazilian beef chain: international competitiveness and strategic responses. In: INTERNATIONAL PENSA CONFERENCE ON AGRIFOOD CHAINS/NETWORKS ECONOMICS AND MANAGEMENT, 5., 2005, Ribeirão Preto Proceedings ... Ribeirão Preto: Faculdade de Economia, Administração e Contabilidade de Ribeirão Preto. Universidade de São Paulo, 2005. 1 CD-ROM

FOOD AND AGRICULTURE ORGANIZATION OF UNITED NATIONS (FAO). Disponível em: 〈http://www.fao.org/>.

FRIGORÍFICO MERCOSUL. Entrevista concedida aos autores em junho de 2006.

JANK, Marcos Sawaya; NASSAR, André Meloni. Competitividade e globalização. In: ZYLBERSZTAJN, Décio; NEVES, Marcos Fava (Org) Economia e gestão dos negócios agroalimentares: indústria de alimentos, indústria de insumos, produção agropecuária, distribuição. São Paulo: Pioneira Thomson Learning, 2005.

KUME, Honório et al. Acordo de livre comércio Mercosul - União Européia: uma estimativa dos impactos no comércio brasileiro. Texto para discussão IPEA, Rio de Janeiro, n. 1054, nov. 2004. Disponível em: <http://www.ipea.gov.br/pub/td/2004/td 1054.pdf >

MIRANDA, Sílvia Helena Galvão de. Quantificação dos efeitos das barreiras não-tarifárias sobre as exportações brasileiras de carne bovina. 2001. 233 f. Tese (Doutorado) - Universidade de São Paulo, Escola Superior de Agricultura Luis de Queiroz, Piracicaba, 2001.

ORGANIZAÇÃO MUNDIAL DO COMÉRCIO (OMC). Disponível em: 〈http://www.wto.org/>.

SAMUELSON, P. Spatial price equilibrium and linear programming. American Economic Review, v. 42, p. 283-303, 1952. 
SULLIVAN, J. et al. A 1989 global database for the Static World Policy Simulation (SWOPSIM) modeling framework: staff report n. AGES 9215. Washington : USDA/Economic Research Service, 1992.

THORSTENSEN, Vera; JANK, Marcos S (Coord.). O Brasil e os grandes temas do comércio internacional. São Paulo: Aduaneiras, 2005.

UNITED STATES DEPARTMENT OF AGRICULTURE (USDA). Disponível em: 〈http://www.usda.gov/wps/portal/usdahome〉.

WAQUIL, Paulo Dabdab. Primal-dual spatial equilibrium model with intermediate products: application to the agricultural sector in the Mercosur. 1995. 249 p. : il. Tese (Doutorado) - University of Wisconsin, Wisconsin, 1995.

Abstract - This paper discusses the perspectives to production, exports, imports, prices and welfare levels (producer surplus and consumer surplus) to the beef sector in the MERCOSUR facing some scenarios of tariffs reductions at the multilateral and regional levels. We use a Spatial Allocation Model formulated as a Mixed Complementarity Problem. We got a base scenario for the world markets, and then we simulated scenarios with reductions of tariffs. In the base scenario, MERCOSUR and Oceania are exporters and the other regions produce for domestic consumption, and some of them are importers. When we analyze the aggregate welfare level in MERCOSUR, the multilateral free trade is the scenario that brings the highest benefits.

Key-words: beef, MERCOSUR, international trade. 
REVISTA DE ECONOMIA E AGRONEGÓCIO, VOL.5, $N^{o} 4$ 